\title{
Double North Pacific High in Summer
}

\author{
Kern E. Kenyon \\ 4632 North lane, Del Mar, USA \\ Email: kernken@aol.com
}

Received 11 April 2016; accepted 23 May 2016; published 26 May 2016

Copyright (C) 2016 by author and Scientific Research Publishing Inc.

This work is licensed under the Creative Commons Attribution International License (CC BY).

http://creativecommons.org/licenses/by/4.0/

(c) (i) 0pen Access

\begin{abstract}
An example of sea level pressure (SLP) and sea surface temperature (SST) is displayed for a summer month based on historical monthly mean data for the North Pacific. A double North Pacific High (NPH) co-occurred with a double large-scale SST maximum along $40 \mathrm{~N}$. Centers of the two NPHs had very nearly the same longitudes as did the SST maxima. Seven similar coincidences happened within the 30-year records. These particular associations between extrema of SLPs and SSTs enhance a previously published conjecture that single and double NPHs are caused by heat transfer from the sea surface to the atmosphere. The eastern SST maximum is the signature of a permanent wide warm surface current flowing northeast off California. To the west of it in the summer is a transient wide warm surge of surface water flowing north as it crosses mid-latitudes. These are the heat sources that generate the single and double NPHs.
\end{abstract}

\section{Keywords}

Double North Pacific High, Double SST Maxima

\section{Introduction}

A particular example in the climatological records of monthly mean temperature and pressure sparks a new investigation into the relationship between relatively high sea surface temperatures and the generation of high sea level pressure. Month and year are July 1956 at mid-latitudes in the central and eastern North Pacific. A double NPH (North Pacific High) coincided in time and place with a double longitudinal maximum in SST (sea surface temperature). This coincidence appears to be no accident, and something further may be learned by a study of it, or at least an expanding awareness of what has already been learned can be the result.

Existing in print is a hypothesis for the generation of the NPH [1]. It starts with the permanent wide warm current flowing northeast off California [2]. Since the air temperature above this current is lower than the water temperature at mid-latitudes, the atmosphere is heated from below within the boundaries of the flow. Then vertical convection will occur bringing down to the sea surface cooler dryer air than what was there before. Cooler dryer air is denser, and if temperature is not an issue, the prefect gas law predicts higher pressure. During March 
and April of 1976 an oceanographic ship sailed across the wide warm current at $35 \mathrm{~N}$ and through the middle of the NPH taking measurements in the air as well as in the water. Later analyses showed that the relative humidity was low just above the warm water compared to that in regions on either side of the current [1], adding support to the hypothesis.

None of the elements in the above chain of reasoning appears to need altering on account of any recent developments. But how does one explain the fact that there is only one wide warm current but on occasion two high pressure centers can exist at the same time? When two NPHs occur in a monthly mean map, one is always in the east over the ocean and it is usually better developed. The weaker one is west of it and slightly south in the majority of cases. Except for the summer months the warm current is considerably longer than it is wide, connecting the western tropical Pacific to the Gulf of Alaska. With such a shape for the heat source one could readily conceive of two separate high pressure cells that each have the same width as the current (about 4000 $\mathrm{km})$.

In the summer the width of the current appears to significantly increase westward in the long term averages of SST, yet it has happened more than once during a 30-year period that a double NPH occurred in a summer monthly mean. What is the explanation then? First, more recent interpretations of the SST data show that there are actually two wide warm currents every summer: one is the permanent year around northeastward flow and the other is a northward surge of warm surface water taking place only in summer and located west of the main flow [3].

If the warm summer surge is immediately adjacent and to the west of the permanent flow, i.e. fused together as one unit, or if the longitudinal separation between them is small (defined below), then there is often a single expanded NPH sitting on top. Normally that is what happens. Suppose, in an unusual situation, that the summer surge were to move northward considerably to the west of the main current with a large separation in longitude of the two SST maxima. Following the lead of the heating hypothesis is the expectation that there could then be two NPHs side by side. Even at the rate of only one summer in 30 years, such a phenomenon would tend to increase confidence in the original hypothesis. But it has happened several more times than that.

\section{Observations}

Climatological data of SSTs and SLPs in my possession cover most of the North Pacific for the 30 years starting with 1947. Ship-injection temperatures had been collected and combined (averaged) into five degree latitude/ longitude blocks and one month bins. This is the unpublished Namias-Scripps SST set, which unfortunately has not been kept up to date. Sea level pressures are available in a similar way (monthly means for 30 years) though spatially formatted in a diamond grid, alternating five degree squares, provided by the Southwest Fisheries Lab [4]. Both compilations I have are hard copies, numbers printed on maps of the North Pacific. For the present purposes magnetic tapes, if they exist, are not needed in order to easily make the basic concept presented here visible.

During ten years in a row beginning with 1950 the monthly SLP maps have selected contours of constant sea level pressure placed on them whereby the highs and the lows show up very clearly. Figure 1 and Figure 2 are taken from that data subset. In the 1970s Dan Cayan of SIO prepared for me computer drawn graphs of SST plotted against longitude for latitudes $25 \mathrm{~N}$ - 50N and for almost 30 years. Figure 3 and Figure 4 came from that unpublished source. Each graph is beautifully done, printed on thin semi-transparent sheets of paper, bound in book form, providing the possibility that three or four consecutive months can be viewed simultaneously and enabling the evolution of the large-scale longitudinal SST patterns to be studied.

Two high pressure cells, separate but equal (in strength), are shown in Figure 1. Their centers are at the same latitude (35N), and the month is July of 1956. It is reasonable to suppose that the makers of this pressure chart almost certainly knew nothing of the contemporaneous sea surface temperatures of the mid-latitude North Pacific. Also Dan Cayan just as likely was unaware of the SLPs of Figure 1 when he made Figure 3 and Figure 4 showing two separate longitudinal maxima of surface temperature along $40 \mathrm{~N}$ that occurred virtually at the same longitudes as those of the high pressure centers in Figure 1. Such a near coincidence has apparently gone unnoticed until now, and should not be ignored any longer because it tends to lend support in a particular and peculiar case to the generation of the high pressure hypothesis, by ocean heating of the atmosphere from below, that arose earlier through consideration of more numerous and more normal conditions. Due to the time averaging of five degree latitude/longitude squares and one month intervals involved in the above figures, an even closer coincidence between the double SLPs and the double SST maxima would not be anticipated. 


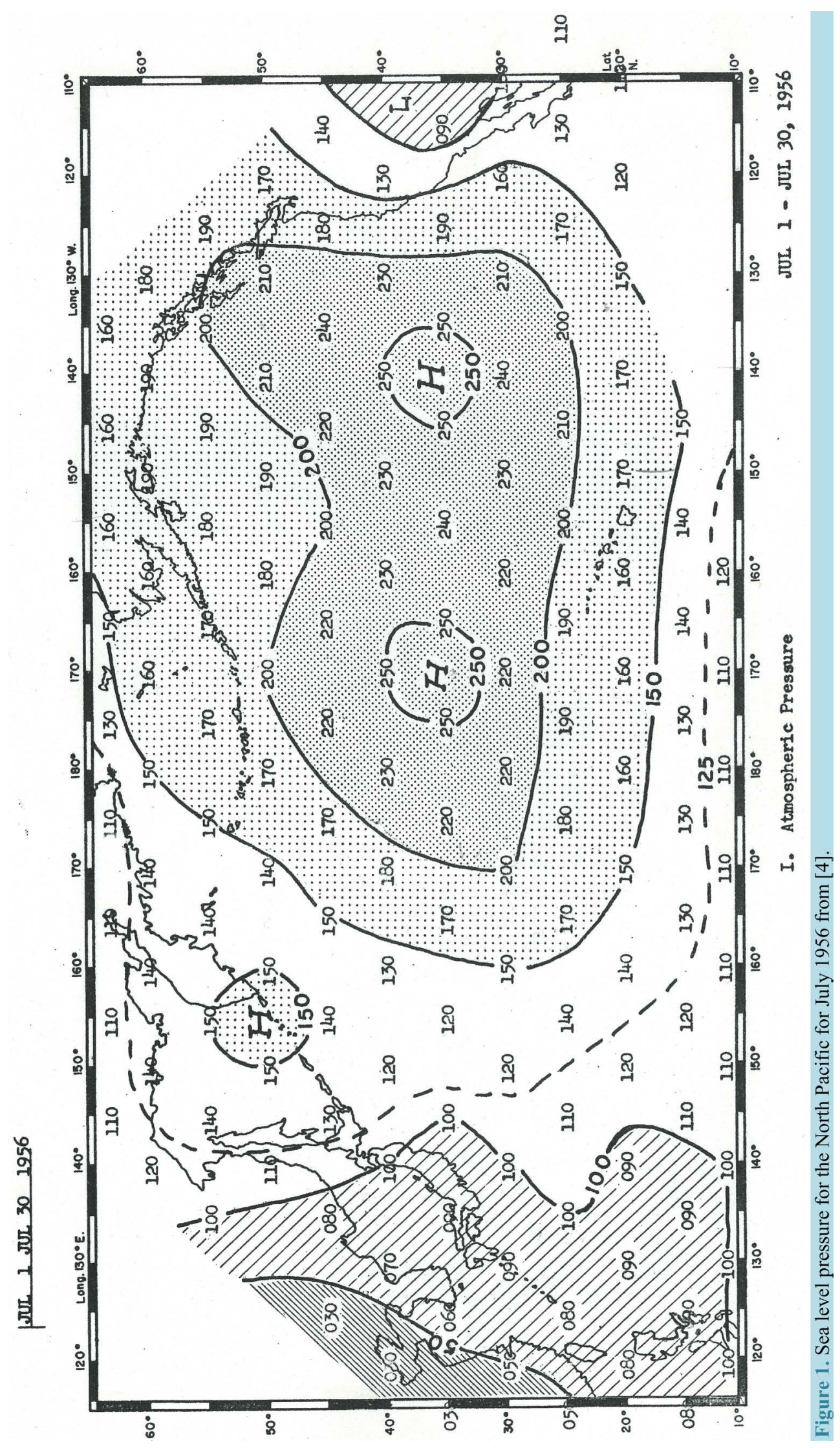




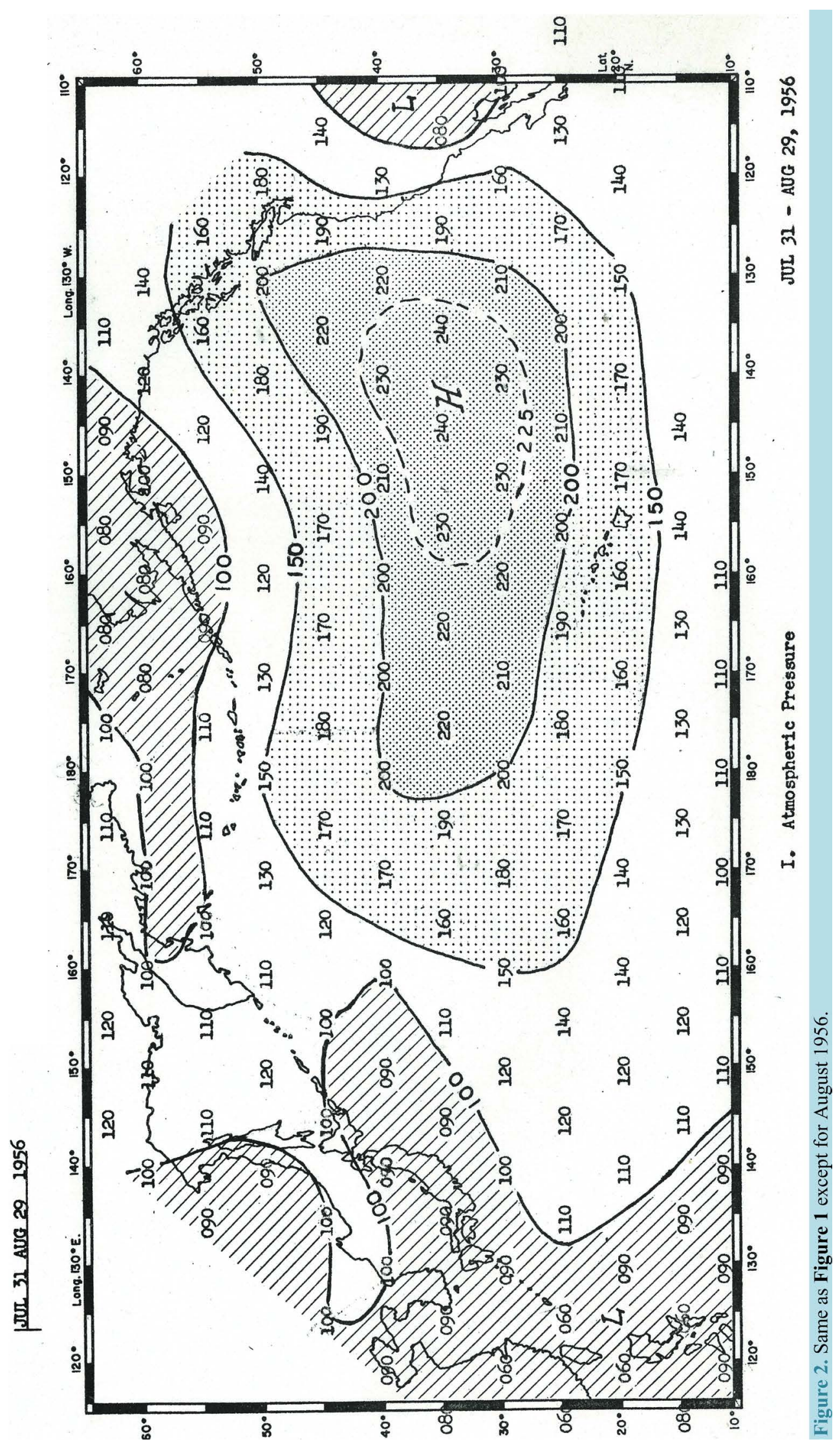




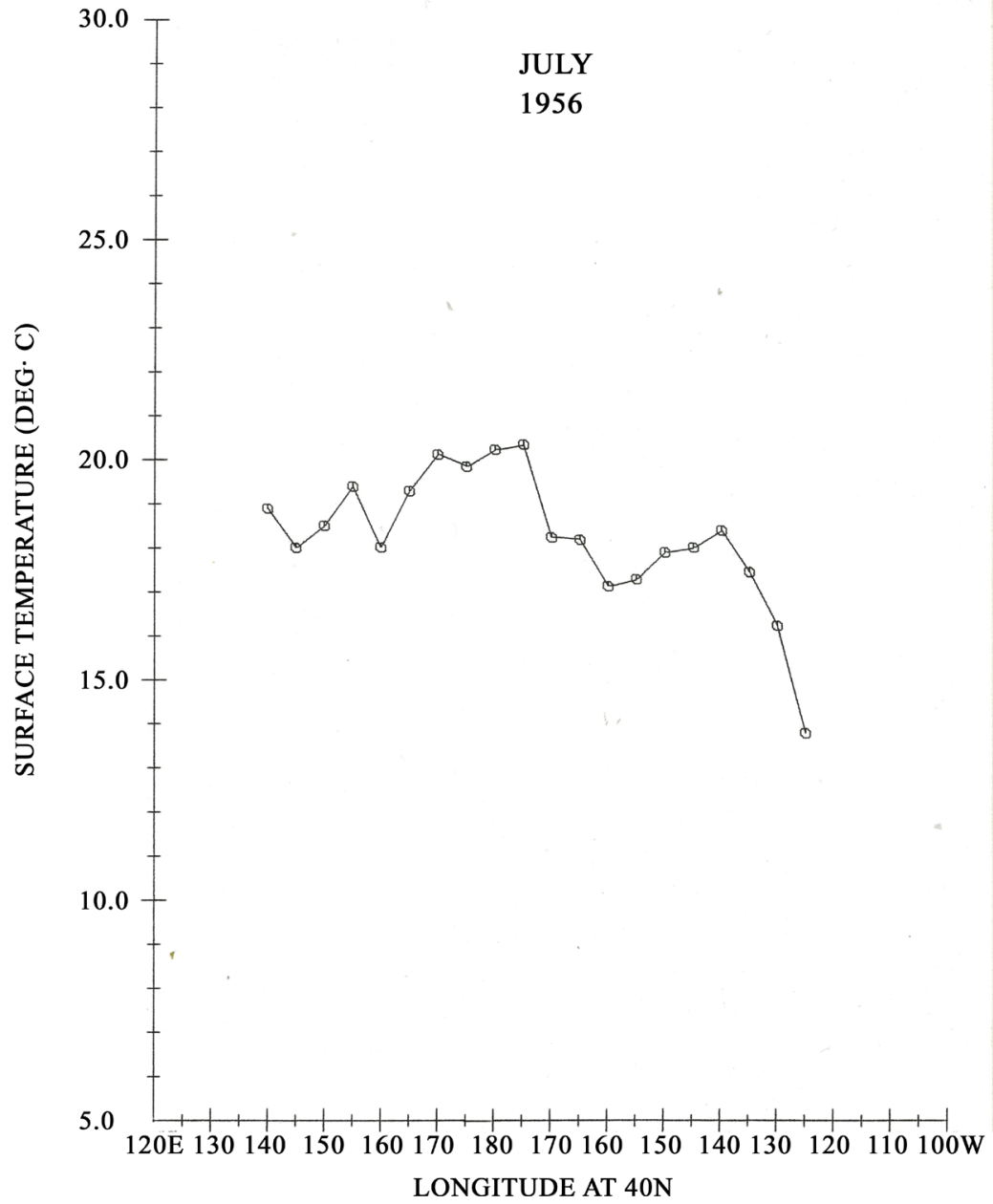

Figure 3. Sea surface temperature along 40N in the Pacific for July 1956 from the Namias-SIO data set.

One question that can logically arise next is: how reliable is the variation with longitude of the western SST maximum near the middle of the ocean in Figure 3 and Figure 4? The permanent SST maximum closer to the North American Continent has been established to be real several times by independent sets of more closely spaced and more accurate temperature measurements taken on individual oceanographic cruises. Independent data comparisons have not been possible to make for the western SST maxima of Figure 3 and Figure 4. However, a consistency check between the two figures is possible, which can be expanded further. In a figure published previously for August 1956 the western SST maximum was present at the same longitude along 35N, 40N and 45N [5], and it existed in July as well. Thus the double SST maximum was apparently more firmly established than the double SLP maximum, which was best expressed for the month of July 1956, with a possible hint of it also in August (Figure 2), according to the available data.

\section{Discussion}

At least seven other examples of a summer double NPH coinciding in time and place with a double longitudinal SST maximum at mid-latitudes can be found within 30 years of 1947 in the monthly mean records, although none is quite as striking as that displayed in Figures 1-4. What appears to be necessary for all these eight examples of the double NPHs in summer, as resolved by the diamond grid, is that the longitudinal separation between the two SST maxima is 40 degrees on the average. There are many more double SST maxima than double NPHs in the summer months, but most of the separations of the SST maxima are smaller than 40 degrees of longitude. Be that as it may, in the author's opinion, collecting all examples together, there should now be even more evidence to support the claim that a single or a double NPH is caused by heat being transferred to the atmosphere 


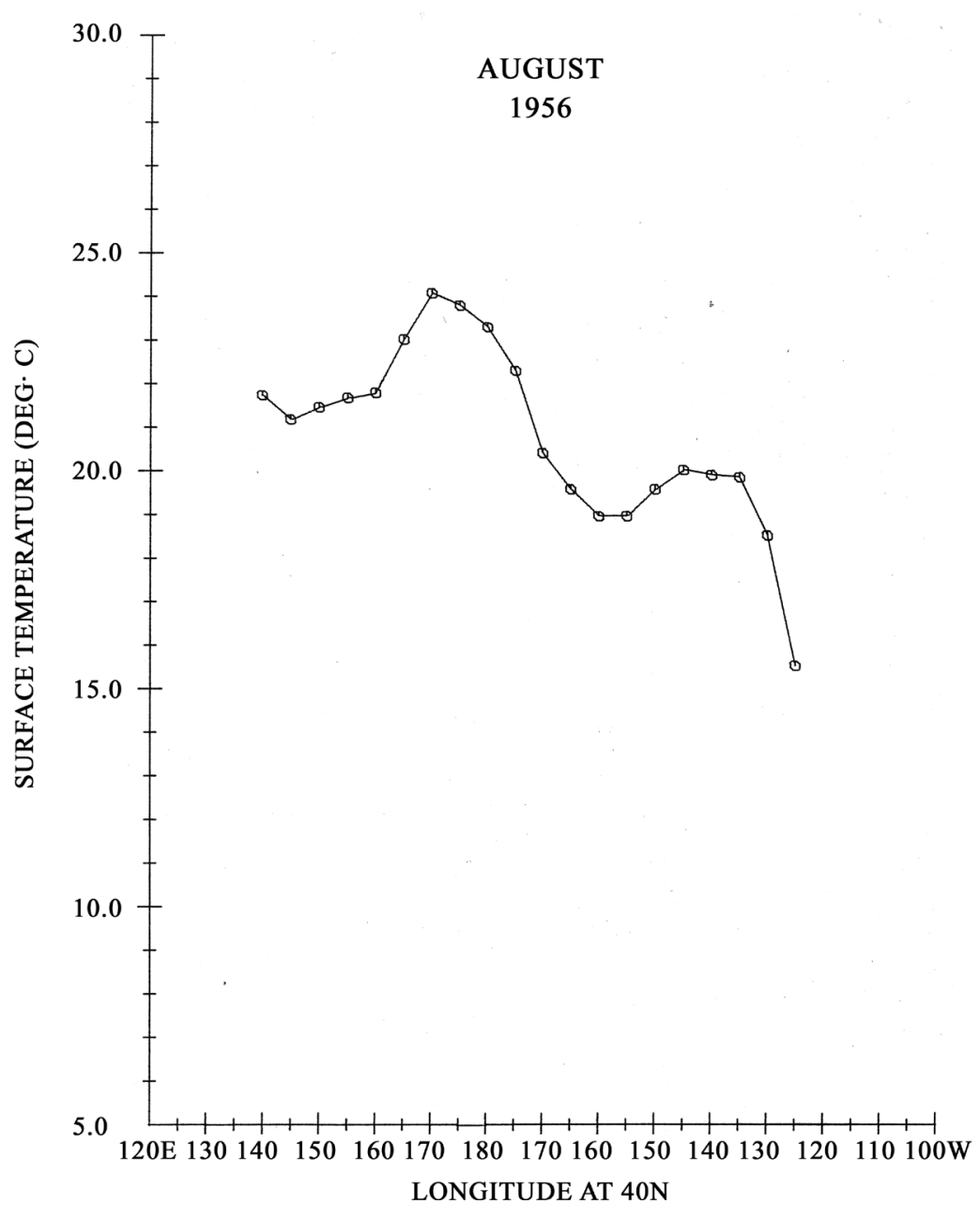

Figure 4. Same as Figure 3 except for August 1956.

from the sea surface over very broad areas.

That big claim leaves out several future possibilities for obtaining further collaborative evidence, since the details of the heat transfer process are not known at this time. For example, how fast can a NPH develop from scratch? When a double NPH occurs, there is some chance of answering the question because the western NPH is not a permanent feature like the eastern one is, but rather a transient phenomenon, particularly in summer. Dealing with monthly mean data, if the development time-scale is less than a month, it cannot be discovered from this information. On the other hand, a time-scale of a few to several months does not seem to be indicated by the data. Therefore, a time of one month or a bit less may be a reasonable but imprecise guess for the growth of an NPH.

Nobody has seen the vertical convection cells above the sea surface that evidently must be involved in the sea to air heat transfer, so the height and width of the cells, as well as the ascending and descending flow rates, are not known. If these quantities could be measured, the results would definitely increase our understanding of the origin of an NPH.

There is an aspect of the time-scale for the growth of the high sea level pressure that is especially relevant to the western cell of a double NPH in summer: the speed of the northward flow of warm surface water, which provides the heat source for the cause of the high pressure. That speed has been variously estimated from observations to be in the range of $10-20 \mathrm{~cm} / \mathrm{sec}$ [3]. Therefore, the rate at which new heat is being delivered to the region of high pressure from the south and west is likely to be $10-20 \mathrm{~cm} / \mathrm{sec}$. Probably not all of the heat brought in is used to build an NPH as evidenced by the fact that longitudinal maxima of SSTs have been found to extend pretty far north right on through and out the other side of an NPH. There is plenty of room for more 
work here.

When a second high forms and makes a double high, this is not in the nature of an exception that proves the rule. Rather both highs are part of the same rule.

Finally, Figure 3 and Figure 4 are one illustration of the greater spatial variability in the large-scale SST patterns that can take place in the middle of the North Pacific at mid-latitudes compared to that in the eastern part of the ocean. Although the permanent wide warm current is nearly locked in position, particularly when it bumps into the North American Continent, the northward summer surge of warm surface water evidently has more freedom of lateral movement from one year to the next. Whether or not there is variability also in the starting time of the surge is probably not discoverable from the monthly mean data.

\section{Conclusion}

An exceptional historical large-scale SST pattern at mid-latitudes of the North Pacific, based on monthly mean ship-injection data averaged over five degree latitude/longitude squares, is shown to correspond to an unusual monthly mean large-scale SLP pattern: a double North Pacific High. Longitudes of the centers of the two high pressure cells are very nearly the same as those of a double SST maximum along 40N. Such a coincidence in a special case is used to increase confidence in an earlier hypothesis for the generation of high pressure at sea level founded on the correlation of more normal characteristics of the SST and SLP distributions. It had been conjectured that high pressure results from heating of the air from below by conduction from the sea surface over a broad horizontal area.

\section{References}

[1] Kenyon, K.E. (1999) North Pacific High: A Hypothesis. Atmospheric Research, 51, 15-34. http://dx.doi.org/10.1016/S0169-8095(98)00110-0

[2] Kenyon, K.E. (2012) The Wide Warm Current of the North Pacific. Lambert Academic Publishing, Saarbrucken.

[3] Kenyon, K.E. (2014) North Pacific Month to Month SST Changes. Natural Science, 6, 1179-1185. http://dx.doi.org/10.4236/ns.2014.614105

[4] Fofonoff, N.P. (1960) Transport Computations for the North Pacific, 1955. Fisheries Research Board of Canada, Manuscript Report Series, No. 78.

[5] Kenyon, K.E. (1977) A Large-Scale Longitudinal Variation in Surface Temperature in the North Pacific. Journal of Physical Oceanography, 7, 256-263, Fig. 6. 